\title{
Assessment and Treatment of Pain in Adult Intensive Care Unit Patients
}

\author{
Jun-Mo Park, M.D., Ph.D. and Ji Hyun Kim, M.D.
}

Department of Anesthesiology and Pain Medicine, Kyungpook National University Hospital, Kyungpook National University School of Medicine, Daegu, Korea

In most cases, patients admitted to an intensive care unit (ICU) have suffered from severe trauma, undergone major surgery or been treated for a serious medical illness. Although they often experience more intense pain than general ward patients, they are frequently unable to communicate their experiences to health care providers, thus preventing accurate assessment and treatment of their pain. If appropriate measures are not taken to treat pain in critically ill patients, stress response or sympathetic overstimulation can lead to complications. The short-term consequences of untreated pain include higher energy expenditure and immunomodulation. Longer-term, untreated pain increases the risk of post-traumatic stress disorder. Because pain is quite subjective, the accurate assessment of pain is very difficult in the patients with impaired communication ability. The current most valid and reliable behavioral pain scales used to assess pain in adult ICU patients are the Behavioral Pain Scale and the Critical-Care Pain Observation Tool. Once pain has been accurately assessed using these methods, various pharmacologic and non-pharmacologic therapies should be performed by the multidisciplinary care team. Accurate assessment and proper treatment of pain in adult ICU patients will improve patients outcome, which reduces the stress response and decreases the risk of post-traumatic stress disorder.

Key Words: intensive care units; nerve block; opioid; pain measurement; posttraumatic stress disorders; sympathetic nervous system.

\section{Introduction}

The pain management is a key aspect of medical professionalism. Since the American Pain Society declared "pain: the fifth vital sign" in 1995, medical professionals became more aware of the importance of management of a wide variety of pain symptoms in their patients, and their level of interest in research on pain management methods have increased.[1] Patients in intensive care unit (ICU) are vulnerable to severe pain as a result of major surgery, severe trauma and serious medical illness requiring invasive mon-

Received on April 15, 2014 Revised on July 7, 2014

Accepted on July 14, 2014

Correspondence to: Jun-Mo Park, Department of Anesthesiology and Pain Medicine, Kyungpook National University Hospital, Kyungpook National University School of Medicine, 130 Dongdeok-ro, Jung-gu, Daegu 700-721, Korea

Tel: +82-53-420-5863, Fax: +82-53-426-2760

E-mail:pjm4013@naver.com

* No potential conflict of interest relevant to this article was reported. itoring, mechanical ventilation and prolonged hospitalization.[2-4] In addition, even routine nursing care, such as dressing change and airway suctioning can be the source of substantial pain for ICU patients.[2-4] ICU patients are in greater need of adequate pain management, compared with general ward patients. However, ICU patients may not receive adequate care and treatment for the pain they go through because of several reasons. In fact, medical professionals may have difficulties identifying and evaluating pain in adult ICU patients, and their pain is often undetected or underestimated in many cases.[5-7] Any difficulty in identifying and evaluating pain in adult ICU patients appears to be associated with adult ICU patient's limited ability to communicate.[8] Patient's communication abilities are further limited when they are intubated. Payen et al.[2] estimated accurate assessment of pain was made in less than $40 \%$ of total mechanically ventilated patients. ICU patient's alertness is also affected by the administration of sedatives and/or analgesics and disease itself progression. Thus most ICU patients may have difficulty communicating the experience of pain and describing the intensity of pain, making it difficult or impos- 
sible for medical professionals to evaluate their pain accurately.[9]

The present article aimed to describe adverse effects that may occur in adult ICU patients when their pain is not properly controlled. The article also addressed pain assessment tools, which have shown to be valid in evaluating pain in adult ICU patients with communication difficulties, and the effectiveness of both pharmacologic and non-pharmacologic management techniques available for them.

\section{The Importance of Adequate Pain Management in ICU}

Stein-Parbury and McKinley[10] reported in their prospective study that most ICU patients suffer pain. To manage the pain properly that ICU patients feel, accurate assessment and appropriate treatment of the pain is the most crucial factor. If pain in ICU patients is not properly managed, short-term side effects such as higher energy expenditure and immunomodulation can occur.[11,12] In addition, the long-term side effects of uncontrolled persistent pain can include even post-traumatic stress disorder.[13]

International Association for the Study of Pain (IASP) defines pain as an unpleasant sensory and emotional experience associated with actual or potential tissue damage, or described in terms of such damage.[14] As shown in this definition, pain is quite subjective, meaning that pain can be described very differently among patients suffering the same medical condition. Nonetheless, certain physiologic signs are commonly anticipated in patients when their pain is not controlled properly. And these responses may result in further adverse effects. Uncontrolled pain can cause deleterious systemic effects on the body by activating neuroendocrine stress, sympathetic overstimulation, excessive catecholamine release and inducing general stress response.[15,16] Then physiological reactions to uncontrolled pain include anxiety, tachycardia, diaphoresis and catabolic metabolism. As indicated in Table 1, those physiological reactions can lead to increased cardiovascular oxy- gen consumption, decreased gastrointestinal motility, tachypnea, altered pulmonary mechanics, water and sodium retention as a result of activation of the renin-angiotensin-aldosterone axis and cytokine production. Persistent chronic pain, when it remains unrelieved, will cause manifold effects, including immune system dysfunction, hypercoagulable states and an increase in thromboembolic disease, altered glucose control, myocardial ischemia, ventilator dyssynchrony, acute restrictive respiratory physiology, and disrupted sleep quality.[17,18] In addition, ICU patients can experience functional impairment as a result of pain-induced respiratory dysfunction and failure of early ambulation, resulting in poor patient outcome and increased mortality risk.[19]

Most adult ICU patients had major surgery, severe trauma or serious medical illness. Their life-threatening critical condition acts as a potent stimulus to sympathetic nervous system (SNS).[20] In response to any stimulus, the SNS triggers the fight-or-flight or stress response, which is the most efficient physiological mechanism contributing to our survival.[21] The stimulation of SNS is also crucial to critically ill patients because it boosts oxygen supply into tissues and allows the vital organs remain intact. However, overactive SNS or persistent SNS stimulation is commonly present in adult ICU patients with critical illness. Chronic overstimulation of the SNS activates the stress response beyond tolerable time period and adaptive scope that exert beneficial effects, causing damaging effects.[20] In particular, the stress response system easily gets out of control when the SNS remains overstimulated during critical illness and causes adverse side effects.[20] Although the ICU is designed to provide intensive care for critically ill patients, the ICU environment itself can be the primary factor inducing stress responses in adult ICU patients. In the critical care setting, noise, sleep deprivation, disturbance of circadian rhythms, a lack of natural light and loss of entitlement increase stress in patients.[22]

Recently, the relationship between the SNS and post-traumatic stress disorder (PTSD) has drawn attention. A study

Table 1. Systemic and physiological responses induced by pain

\begin{tabular}{ll}
\hline \hline System & \multicolumn{1}{c}{ Effect } \\
\hline Cardiovascular & Increased myocardial oxygen demand \\
Respiratory & Hyperventilation, lowered residual capacity, ventilator dyssynchrony, atelectasis, hypoxia \\
Gastrointestinal & Decreased motility \\
Renal & Activation of the renin-angiotensin-aldosterone system \\
Endocrine & Hyperglycemia and hypotension due to hormonal imbalance, especially cortisol and insulin, increased catabolism \\
Hematological & Hypercoagulability and platelet dysfunction, increased risk of thromboembolic disease and gastrointestinal bleeding \\
Psychological & Depression, fatigue, psychosis, anxiety, sleep disturbance and serotonergic imbalance \\
Immune & Suppressed immunomodulation through cytokine elaboration and leukocyte dysfunction (especially NK cells) \\
\hline
\end{tabular}

NK cells: natural killer cells. 
claimed $20 \%$ to $25 \%$ of ICU patients developed PTSD.[23] Also, PTSD patients were characterized by the SNS chronically activated over the normal baseline levels.[24,25] PTSD patients also show elevated urinary norepinephrine[26] and significantly higher level of norepinephrine concentrations in cerebrospinal fluid, compared with the control group.[27] Norepinephrine concentration levels were correlated with the severity of PTSD symptoms, according to the latter study. The findings of increased noradrenergic activity among PTSD patients suggest a decrease in central nervous system noradrenergic activity would effectively treat arousal symptoms such as nightmares and startle reactions.[28]

\section{Pain Assessment for Adult ICU Patients}

As mentioned above, pain is defined as a subjective experience by IASP. That is, patients should be able to describe the pain they are experiencing to have their pain assessed accurately and treated properly. At the same time, the intensity of pain felt can vary among patients even when the source of their pain is identical. While patient's subjective descriptions of pain characteristics are required for accurate assessment of their pain, many patients in the ICU have impaired communication ability, meaning that they may be unable to express their pain experience although their critical physical and mental conditions amplify their pain. Thus accurate pain assessment can be difficult when patients are impaired in their ability to communicate.[9] In fact, it is known that adult ICU patients experience pain on a daily basis even during routine care. Procedural pain is also common in the ICU.[29] Therefore, accurate understanding of their chronic and severe pain should be the first step in managing pain effectively. In addition to the essential understanding of the presence of pain, a routine and repetitive systemic assessment approach is necessary to evaluate the intensity and characteristics of the perceived pain.[29-31] As the IASP described, "the inability to communicate verbally does not negate the possibility that an individual is experiencing pain and is in need of appropriate pain-relieving treatment," it can be wrong if medical professionals do not provide adequate pain management in adult ICU patients who are not able to describe the pain in the mistaken assumption that they have no pain.[14] Routine pain assessment leads to improved clinical outcomes, and the newly released clinical practice guidelines of the Society of Critical Care Medicine (2012 SCCM guideline) strongly recommends the implementation of routine pain assessment.[29] In partic- ular, a standardized pain management protocol can significantly reduce sedative dose, the length of ICU stay and the length of intubation period.[2,32]

Ideally, pain assessing practices in the ICU should identify the characteristics of pain, including location, duration, type, intensity and exacerbating and relieving factors, if possible, not to mention the presence or absence of pain.[33] There are also subtypes of pain, which are categorized as somatic, visceral, neuropathic and mixed. Because these subtypes also affect pain characteristics and management, they should be identified.[30] Their pain is mostly somatic pain, which is typically dull and aching pain and often well-localized while responds well to opioids and non-steroidal anti-inflammatory drugs (NSAIDs). Visceral pain occurs when bowels are not properly treated and when there is underlying gastrointestinal pathology. This abdominal pain is cramping and colicky but responds promptly to anticholinergics. Although it is not well documented in ICU patients, neuropathic pain also exists in symptoms of burning and shooting pain along the distribution of the affected nerve root. Antidepressants and anticonvulsants are commonly used for the management of neuropathic pain.[30,33]

It is however difficult for ICU physicians to predict the onset of pain and clarify the correlation between the new-onset pain and physiological changes such as hypertension, tachycardia and tachypnea.[29] Therefore, patient's self-reporting is regarded as the gold standard of pain assessment.[9,34] Pain scales such as visual analog pain scale (VAS) and numerical rating pain scale (NRS) are used to measure intensity of pain in patients with self-report abilities.[35] These tools cannot be applied to many adult ICU patients because they are unable to self-report with limited verbal capabilities.

American Society for Pain Management Nursing recommended proper treatment after the cause of pain is identified through the meticulous evaluation of pain-related behaviors of patients being intubated or having cognitive deficits.[36] Since these patients tend to have communication difficulties, their vital signs are sometimes used as alternative pain indicators. However, the 2012 SCCM guidelines recommend not using vital signs alone for pain assessment in critically ill adult patients.[29] Nonetherless, it does not mean that changes in vital signs are useless for pain assessment. It is a well-known fact that changes in vital signs can provide important clues to enable closer examination or diagnosis.[36,37] Medical professionals therefore rely on behavioral measures when evaluating pains in adult ICU patients with inability to communicate verbally.[5,9,37,38] Behavioral measures in cognitively impaired adults examine common 
pain-related responses or actions, including muscle tension, differences in body postures, startling facial expression, psychomotor agitation and patient-ventilator dyssynchrony (bucking the ventilator).[39-41]

When ICU patients' motor function remains intact and their pain behavior is observable except brain injury patients, even though they cannot provide a self-report, the 2012 SCCM guidelines recommends Behavioral Pain Scale (BPS) and CriticalCare Pain Observation Tool (CPOT) as valid tools for accurately assessing pain.[29] These nonverbal scales proved successful assessing pain among adult ICU patients given the quality of psychometric evidences although the scales still have some limitations.[29] BPS has been most commonly used to assess pain through evaluate facial expression, upper limb movements, ventilation compliance. The BPS score (total score: $3-12$ ) is the sum of three behavioral domains that had a range of score of 1-4.[42] Although BPS is known to be relatively accurate in evaluating pain in mechanically ventilated patients or those receiving sedation, the scale cannot be applied to non-intubated patients. Behavioral Pain scale-Non-Intubated (BPS-NI) is a modified BPS to evaluate pain in spontaneously breathing patients who cannot self-report. In BPS-NI, compliance with ventilation of BPS is replaced with vocalization.[43] CPOT is useful in assessing pain of spontaneously breathing patients.[44] The CPOT score (total score: $0-8$ ) indicates the sum score of four behavioral domains: facial expression, body movements, muscle tension and compliance with the ventilator or vocalization. Each item is scored from 0 to 2 . The item of 'compliance with the ventilator or vocalization' makes this tool suitable for assessing pain in spontaneously breathing patients. A CPOT sore of 2 or higher show a sensitivity of $86 \%$ and a specificity of $78 \%$ when predicting significant pain in postoperative adult ICU patients who underwent a nociceptive procedure.[40,45] These sensitivity and specificity levels of the CPOT are considered similar to a BPS score of greater than 5 , making it possible to predict that nonverbal adult ICU patients have significant pain during nociceptive procedure, compared with patients at rest.[32]

While studies conducting pain assessment based on pain-related behaviors are still not enough, either BPS or CPOT has become the mainstay of pain assessment in ventilated patients. CPOT is widely used for pain assessment in spontaneous breathing patients who cannot self-report. Separately, BPS-NI is regarded as an effective tool for assessing pain in non-intubated patients unable to self-report due to delirium and subsequent cognitive impairment.[5]

\section{Pain Treatment for Adult ICU Patients}

Pain management methods for adult ICU patients are largely classified into pharmacologic and non-pharmacologic methods.[29] However, the most important requisite for pain management is to check whether there are any other possible causes of pain before undertaking any of these therapies.[3,4] Identification of potential causes of pain should be prioritized. Once other causes of pain are identified, medical professionals should implement corrective actions to remove them. Their actions may include patient repositioning, stabilization of injury and/or fractures, removal of noxious or irritating stimuli (e.g., proper positioning of ventilator tubing to avoid traction on the endotracheal tube), and application of heat or cold.[3,4] If pain remains persistent even after doing corrective actions properly, physicians can undertake either pharmacologic or non-pharmacologic therapy.

Table 2. Pharmacology of commonly used opioids

\begin{tabular}{|c|c|c|c|c|c|}
\hline Opiates & Metabolism & $\begin{array}{l}\text { Onset/ } \\
\text { duration }\end{array}$ & $\begin{array}{c}\text { Dose } \\
\text { (bolus/maintenance) }\end{array}$ & Advantages & Disadvantages \\
\hline Fentanyl & N-dealkylation & $\begin{array}{c}1-2 \mathrm{~min} / 2-4 \mathrm{hr} \\
\text { (longer in liver failure) }\end{array}$ & $\begin{array}{c}25-50 \mu \mathrm{g} \text { IV push/ } \\
12.5-200 \mu \mathrm{g} / \mathrm{hr} \\
\text { continuous infusion }\end{array}$ & $\begin{array}{l}\text { Less hypotension than } \\
\text { with morphine }\end{array}$ & $\begin{array}{c}\text { Accumulates with hepatic } \\
\text { dysfunction }\end{array}$ \\
\hline Hydromorphone & Hepatic & $\begin{array}{l}5-15 \mathrm{~min} / 2-3 \mathrm{hr} \\
\text { (longer in liver failure) }\end{array}$ & $\begin{array}{c}1-4 \mathrm{mg} \text { IV push/ } \\
0.25-50 \mathrm{mg} / \mathrm{hr} \\
\text { (no real maximum dose) }\end{array}$ & $\begin{array}{l}\text { Can be used in patients } \\
\text { tolerant to morphine or } \\
\text { fentanyl }\end{array}$ & $\begin{array}{l}\text { Accumulates with } \\
\text { hepatic/renal dysfunction }\end{array}$ \\
\hline Morphine & $\begin{array}{c}\text { Hepatic/renal } \\
\text { (active metabolite) }\end{array}$ & $\begin{array}{c}5-10 \mathrm{~min} / 3-4 \mathrm{hr} \\
\text { (longer in liver failure } \\
\text { and ESRD) }\end{array}$ & $\begin{array}{c}2-4 \mathrm{mg} \text { IV push/ } \\
0.5-49 \mathrm{mg} / \mathrm{hr}\end{array}$ & $\begin{array}{c}\text { May be preferred in } \\
\text { patients with } \\
\text { tachyphylaxis to fentanyl }\end{array}$ & $\begin{array}{l}\text { Accumulates with } \\
\text { hepatic/renal dysfunction } \\
\text { histamine release }\end{array}$ \\
\hline Remifentanil & Plasma esterase & $1-3 \mathrm{~min} / 3-10 \mathrm{~min}$ & $\begin{array}{c}1 \mu \mathrm{g} / \mathrm{kg} \text { over } 1 \mathrm{~min} \text { IV push/ } \\
0.6-15 \mu \mathrm{g} / \mathrm{kg} / \mathrm{hr} \\
\text { (use IBW if more than } 30 \% \\
\text { over IBW) }\end{array}$ & $\begin{array}{l}\text { No accumulation in } \\
\text { hepatic/renal dysfunction }\end{array}$ & $\begin{array}{c}\text { Can cause bradycardia and } \\
\text { hypotension } \\
\text { Use IBW if body weight }> \\
130 \% \text { IBW }\end{array}$ \\
\hline
\end{tabular}

ESRD: end stage renal disease; IBW: ideal body weight. 


\section{1) Pharmacologic therapies}

Medical professionals may be surprised to learn that one of the most painful and distressing procedures for adult ICU patients is turning.[46] Nonetheless, adult ICU patients are rarely premedicated to undergo pain provoking procedures such as turning. Patient's communication difficulties may be one of the reasons for rare premedication. Given limited communication ability among adult ICU patients, pharmacologic therapy through intravenous (IV) route is the most commonly used method for the management of pain in adult ICU patients because it is easy to administer drugs without changing the posture of the patients.[3,47,48] A pharmacologic therapy for pain management should be chosen on the basis of pharmacokinetic and pharmacodynamic properties as described in Table 2. Potential drug-related side effects should be also noted.[31]

The 2012 SCCM guidelines recommends IV opioids such as fentanyl, hydromorphone, morphine, methadone and remifentanil as the first-line treatment for non-neuropathic pain in adult ICU patients.[29] IV opioids are widely used because they are adequately potent without ceiling effects and have mild sedative and anxiolytic effects.[30] These drugs are therapeutically equivalent in terms of analgesic effects. Opioids can cause side effects, and therapeutic doses should be reduced or discontinued in the presence of side effects, which include respiratory depression, altered mental status, decreased gastrointestinal motility, hypotension, nausea and/or vomiting, pruritus, flushing, urinary retention, and delirium.[31] However, these side effects can be very serious, depending on patient condition. As described in Table 2, properties and side effects can vary with the class of opioids, in addition to properties and side effects common to all opioids. Consideration should be therefore given to the expected effectiveness and side effects of opioids before administration.[29] Differences in lipid solubility, volume of distribution, half-life, clearance, metabolism, and active metabolites, caused by different opioids, produce different effects on onset, peak, and offset of action, potency, and the influence of renal or hepatic dysfunction.[31] The use of morphine sulfate requires caution because morphine-6-glucuronide, which is active as much as morphine sulfate as one of major active metabolites of morphine, can be accumulated in the presence of renal failure. Accumulation of morphine-6-glucuronide can cause unnecessarily excessive prolongation of analgesic effect, somnolence and respiratory depression.[49] Fentanyl is a synthetic opioid that achieves rapid equilibration from plasma to lipid-rich brain tissue for its rapid onset of action, which leads to high lipophilicity-induced large volume of distribution and delayed offset of action after prolonged infusion.[50] Remifentanil, one of fentanyl derivates, has small volume of distribution and is rapidly metabolized by esterases, showing short half-life and rapid offset of action regardless renal and hepatic function.[51,52] Hydromorphone has pharmacokinetic and pharmacodynamic profiles similar to those of morphine. As a more potent congener of morphine, hydromorphone produces little histamine release without much adverse effects on the central nervous system, making it an alternative to morphine.[53] Methadone delays development of tolerance when used with other opioids, but its continuous infusion is not possible because of the difficulty in predicting pharmacokinetics.[38] Methadone is a strong medicine that prolongs the rate-corrected QT interval.[54,55] Meperidine has the potential to cause neuroexcitatory adverse effects such as seizure.[49] It is not therefore recommended for ICU patients.[29]

Pain management for adult ICU patients requires accurate knowledge about possible side effects associated with these drugs. At the same time, it is also crucial to avoid unnecessary side effects and treat unavoidable side effects with accurate information. If side effects are intolerable, the dose should be reduced to the lowest effective level.[33] If pain is not relieved by opioids alone or side effects by opioids become intolerable, the use of non-opioids or atypical analgesics is recommended or IV opioids can be replaced by epidural analgesia, other peripheral nerve block techniques, or complementary non-pharmacologic interventions.[31]

Although pain management for adult ICU patients by nonopioid analgesics is supported by limited evidence until now, the 2012 SCCM guidelines suggested the use of non-opioid analgesics for non-neuropathic pain to decrease total quantity of opioids, eliminate the need for IV opioids altogether and decrease opioid-related side effects.[29] Non-opioid analgesics include corticosteroids, local anesthetics (lidocaine, bupivacaine), NSAIDs (ketorolac, ibuprofen), IV acetaminophen, ketamine, adenosine and anticonvulsants. The efficacy of non-opioid analgesics has been proven in postoperative patients and various categories of non-critically ill populations.[29,56-61] However, the efficacy and safety of non-opioid analgesics alone in ICU patients have been less investigated while the previous studies were limited to postoperative settings. Therefore, results cannot be generalized to all ICU patients.[29] The previous studies claimed IV acetaminophen and ketamine were relatively effective to manage pain in ICU patients.[62-64] It is confirmed that IV acetaminophen is effective and safe to control postoperative pain in combination with opioids after major or cardiac surgery. Recently the United States approved use. However, chronic use 
of IV acetaminophen can increase to the risk of developing hepatotoxicity, and long-term use should be avoided.[30,62,65,66] Corticosteroids, ketamine, and adenosine also have potential benefit as adjuvant due to opioids sparing effects. However, the efficacy of these medications on ICU patients is not supported by enough evidence.[60,61] Ketorolac, one of IV NSAIDs, has anti-inflammatory effects but increases the risk of gastrointestinal toxicity and bleeding, making its use restricted in the ICU setting if patients have the risk of bleeding. In a latter case, Ketorolac should be administered for less than 5 days.[30] Despite its possible role as an adjuvant treatment for complex or neuropathic syndromes, lidocaine is also restricted to use for ICU patients, because of the potential to cause arrhythmia.[67] Clonidine and its isomer dexmedetomidine are alpha agonists having mild sedative and analgesic effects. Dexmedetomidine is increasingly used as a sedative for adult ICU patients breathing spontaneously or weaning from ventilation because it causes less respiratory depression.[68]

To control neuropathic pain in adult ICU patients, enterally administered gabapentin or carbamazepine, in addition to IV opioids, are shown to be more effective than opioids alone, as strongly recommended by the 2012 SCCM guidelines.[29] Drug-based neuropathic pain treatment has been widely explored in non-ICU patients through randomized controlled trials despite some limitations of trials, including small sample sizes and the presence of side effects. Drugs used for neuropathic pain treatment include tricyclic antidepressants, selective serotonin receptor inhibitors, serotonin and norepinephrine reuptake inhibitors, anticonvulsants, tramadol, dextromethorphan, ketamine, topical capsaicin, lidocaine patch or gel and cannabinoids.[69]

When choosing drugs for pain management, dosing method along with types of drug are important.[29] Once the type of drugs is decided, whether the drug will be administered intermittently or continuous IV should be chosen based on comprehensive factors, including pharmacokinetics, pain frequency and severity, and/or patient consciousness.[70] For enteral administration of opioids and other drugs, patient's gastrointestinal absorptive capacity and motility should be properly maintained.

\section{2) Non-pharmacologic therapies}

The use of systemic opioids alone is not often enough to manage pain in adult ICU patients, and sometimes other target-oriented techniques are performed to boost pain relief.[18] In case of an aged patient having difficulty breathing due to pain associated with multiple rib fractures, the use of opioids may increase the risk of too deep sedation and obtundity. But epidural or paravertebral catheterization can be a better choice in that case because it makes respiratory and physical therapy possible at the same time while the patient breathe on his or her own. Regional analgesic techniques are employed when pain is not relieved by opioids alone, pain is well localized or risky side effects are expected as a result of opioids. These techniques are also used when they are considered as effective as IV opioids but their systemic side effects will be far less than opioid-induced side effects.[18,30] In addition to the most commonly used epidural analgesia technique, various peripheral nerve block techniques are available for pain relief in adult ICU patients.[71]

Epidural analgesia (EA) is the best known regional analgesic technique for pain management in adult ICU patients.[71] The 2012 SCCM guidelines recommends thoracic epidural anesthetic/analgesic technique for postoperative pain management in patients exposed to abdominal aortic surgery (AAA) or traumatic rib fractures.[29] However, lumbar EA is not recommended over parenteral opioids in patients exposed to AAA surgery. Also, thoracic EA is not recommended in patients exposed to thoracic or non-vascular abdominal surgical procedures.[29] Neuraxial/ regional analgesia is not recommended over systemic analgesia in medical ICU patients.[29] EA in pain management has provided more pain relief and less opioid side effects than IV opioids alone when thoracic EA was combined with bupivacaine and morphine.[72,73] Also, EA led to reduced incidence of postoperative thromboembolism or myocardial infarction and improved bowel and pulmonary function in high risk group of patients.[74] In Cochrane reviews comparing the effectiveness of EA and systemic opioids in patients exposed to elective abdominal surgery, EA not only outpaced opioids in pain relief but reduced the length of intubation period and the incidence of cardiovascular and gastrointestinal complications and acute renal failure.[75] A study that used National Trauma Data Bank revealed a positive correlation between the number of rib fractures and extrapulmonary complications and that mortality risk significantly increased in patients with more than 6 rib fractures, compared with those with less than 6 rib fractures.[18] EA resulted in reductions in morbidity and mortality, particularly in patients with more than 4 rib fractures. Despite these positive benefits, most studies failed to verify the effects of EA on other factors such as ICU stay, hospital stay and mortality. Aside from the above mentioned benefits, EA has some limitations, which make it difficult for medical professionals to utilize for adult ICU patients. Low[76] reported that $89 \%$ of 159 units performed epidural analgesia in a postal questionnaire survey conducted with 216 general ICU in England in 2002. However, just only 51 
Table 3. Peripheral nerve blocks can be used in the ICU patients

\begin{tabular}{|c|c|c|c|c|}
\hline Block & Indications & Contraindications & Practical problems & $\begin{array}{l}\text { Dose suggestions } \\
\text { (bolus/continuous) }\end{array}$ \\
\hline Interscalene & Shoulder/arm pain & $\begin{array}{l}\text { Untreated contralateral } \\
\text { pneumothorax } \\
\text { Dependence on diaphragmatic } \\
\text { breathing } \\
\text { Contralateral vocal cord palsy } \\
\text { Reduced functional residual } \\
\text { capacity }\end{array}$ & $\begin{array}{l}\text { Horner syndrome may obscure } \\
\text { neurologic assessment } \\
\text { Block of ipsilateral phrenic nerve } \\
\text { Close proximity to tracheostomy } \\
\text { and jugular vein catheter sites }\end{array}$ & $\begin{array}{l}10 \mathrm{ml} \text { of } 0.25 \% \text { bupivacaine } \\
\text { or } 0.2 \% \text { ropivacaine every } \\
8-12 \mathrm{hr} \text { and on demand } / 0.125 \% \\
\text { bupivacaine or } 0.1-0.2 \% \\
\text { ropivacaine at } 5 \mathrm{ml} / \mathrm{hr}\end{array}$ \\
\hline Axillary & Arm/hand & & $\begin{array}{l}\text { Arm positioning } \\
\text { Not suitable for catheter } \\
\text { positioning }\end{array}$ & Same with infraclavicular \\
\hline $\begin{array}{l}\text { Infraclavicular/ } \\
\text { supraclavicular }\end{array}$ & Arm/hand pain & $\begin{array}{l}\text { Severe coagulopathy } \\
\text { Untreated contralateral } \\
\text { pneumothorax }\end{array}$ & $\begin{array}{l}\text { Pneumothorax } \\
\text { Interference with subclavian } \\
\text { central venous catheters }\end{array}$ & $\begin{array}{c}10-20 \mathrm{ml} \text { of } 0.25 \% \text { bupivacaine } \\
\text { or } 0.2 \% \text { ropivacaine every } 8-12 \\
\mathrm{hr} \text { and on demand } / 0.125 \% \\
\text { bupivacaine or } 0.1-0.2 \% \\
\text { ropivacaine at } 5-10 \mathrm{ml} / \mathrm{hr}\end{array}$ \\
\hline $\begin{array}{l}\text { Paravertebral } \\
\text { (cervical) }\end{array}$ & Shoulder/elbow/wrist & & $\begin{array}{l}\text { Horner syndrome may obscure } \\
\text { neurologic assessment } \\
\text { Block of ipsilateral phrenic nerve } \\
\text { Patient positioning }\end{array}$ & Same with interscalene \\
\hline $\begin{array}{l}\text { Paravertebral } \\
\text { (thoracic/ } \\
\text { lumbar) }\end{array}$ & $\begin{array}{l}\text { Unilateral chest or } \\
\text { abdomen restricted to } \\
\text { few dermatomes }\end{array}$ & $\begin{array}{l}\text { Severe coagulopathy } \\
\text { Untreated contralateral } \\
\text { pneumothorax }\end{array}$ & Patient positioning & Same with infraclavicular \\
\hline $\begin{array}{l}\text { Femoral and/or } \\
\text { sciatic }\end{array}$ & $\begin{array}{l}\text { Unilateral lower } \\
\text { extremity }\end{array}$ & Severe coagulopathy & $\begin{array}{l}\text { Patient positioning } \\
\text { Interference of femoral nerve } \\
\text { catheters with femoral catheters }\end{array}$ & Same with infraclavicular \\
\hline
\end{tabular}

All the above-mentioned peripheral nerve blocks are contraindicated in the following conditions: patient refusal, local infection at the needle insertion site, preexisting neuropathy, local anesthetic allergies. ICU: intensive care unit.

units $(32 \%)$ used guidelines for EA administration in ICU patients. In fact, there were no consensus guidelines for the management of EA in many cases of bacteremia, sepsis, systemic inflammatory response syndrome or coagulopathy. Because of immunomodulating properties of opioid, EA also increase the risk of infection in the epidural space when performed for ICU patients receiving IV opioids.[77,78] When an epidural catheter is required for prolonged analgesia, EA becomes more difficult to perform, requiring a longer procedure time and increasing risk of infection, depending patient's condition.

As described in Table 3, there are also peripheral nerve block techniques useful for adult ICU patients. These regional analgesic techniques are particularly effective as a pain management tool for patients who have surgery that required a short operation time.[18] The techniques have also proven effective in morbidly obese patients with obstructive sleep apnea and those who develop hypersensitivity to the respiratory depression with opioids. Nowadays nerve block techniques have become safer and simpler by the use of ultrasound as an aid. A limited number of peripheral nerve block techniques are available for adult ICU patients, because they are able to maintain only supine or lateral decubitus position in many cases.[79] The peripheral nerve blocks that can be performed in the upper part of the body include interscalenene, paravertebral (cervical and thoracic), infraclavicular and axillary blocks. The procedures can be performed in the lower part of the body include paravertebral (lumbar), femoral and sciatic nerve blocks. Indications and contraindications for these procedures are shown in Table 3.

Paravertebral block can be performed on either side of the patient and limit diffusion of anesthetic up to 1 or 2 dermatomes from the needle insertion site, meaning that side effects that may occur with a wide block can be therefore prevented.[18] If a wider diffusion or continuous infusion of anesthetic is necessary, catheterization can be performed. Multiple catheterizations also enable a wider diffusion of anesthetic on one side of the chest. However, there is always a possibility of pneumothorax and hemothorax. Multiple catheterizations are not recommended over EA in patients with localized chest trauma or chest tube induced pain.[18] For patients with rib fractures, intercostal nerve block is effective for pain management when they need large amounts of opioids to relieve severe pain caused by movements because even a single fracture can affect the ability to 
breath and induces pulmonary complication. When EA is contraindicated, intercostal nerve block can be a good alternative. However, like other regional analgesic techniques, the effectiveness of intercostal nerve block in adult ICU patients is limitedly known. Besides, multiple injections above and below the injured rib are required for proper pain management and duration of analgesic effect is short up to 4 to 8 hours. Intercostal nerve block cannot be continuously infused because of a high risk of complications. In addition, intercostal nerve block can increase the risk of systemic local anesthetic toxicity as a result of higher local anesthetic serum concentrations in patients with more than 1 or 2 rib fractures, compared with those of peripheral or neuraxial nerve blocks.[18] Femoral nerve block is very useful approach for acute preoperative pain after femoral neck fracture occurs.[80,81] Fascia iliaca compartment block can be also employed in that case.[82,83] A combination of femoral nerve block and sciatic nerve block is also used as a anesthetic in surgical treatment like external fixation apart from its role in pain control.[84]

Although clinical outcomes of regional analgesia were not always beneficial, some studies showed good results.[72,75,85,86] A study reported that neuraxial analgesic techniques reduced the length of intubation period and incidence of pneumonia.[87] Although further evidence is required, increasing studies stress a correlation between the use of narcotics and sedatives and occurrence of delirium and cognitive dysfunction.[68,88,89] Regional analgesia can reduce these adverse effects when properly used.[18] To choose an adequate procedure for patients, physicians should make sure patient's systemic and regional state and have accurate anatomical knowledge on procedure site. Physicians appear to be capable of devising a new technique when they have established enough experiences in nerve block procedures with deep broad knowledge in anatomy and physiology.

Adult ICU patients do not have conditions ideal for regional analgesia, excluding regional anesthesia for postoperative analgesia.[18,30] Most of adult ICU patients cannot maintain body posture required by different anesthetic techniques, and their tissue edema and anatomic deformity may make a needle or catheter placement difficult. Recently advanced ultrasound scanners are lightweight and miniaturized, making them easy to use for patients with limited capability to make movements or postural adjustments. Physicians can carry this portable device to them to perform regional analgesia and check patient's anatomy via ultrasound on a real time bases.[90,91] Ultrasoundguided peripheral nerve blocks demonstrated high success and low complication rates. When patients undergo opioid-based pain treatment, opioid dose is a major factor to decide, and dose is frequently adjusted or discontinued even in patients, who need substantial amounts of opioids, to prevent side effects. As part of the efforts to prevent side effects of opioids, peripheral nerve blocks were employed, and these procedures successfully controlled pain using small amounts of opioid or no opioid. $[92,93]$ In adult ICU patients, keeping a needle or catheter in place is hard as much as placing them in the right place.[30] $\mathrm{A}$ catheter lodged in the right place can be easily dislodged by the patient's agitation, routine nursing care, radiological test and routine daily activities in the ICU. Nonetheless, catheter malposition cannot be checked in many cases as a consequence of altered states of consciousness, coagulation status and risk of transport. In the perioperative setting, a needle or catheter placement increases the risk of complications in adult ICU patients with coagulopathy or thrombocytopenia and taking drugs that affect hemostasis. This kind of risk can be reduced by consistent check about clotting function. However, catheter-associated complication can happen in the course of treatment of critical illness and even after the placement of potentially risky catheter. With regard to patients receiving anticoagulation therapy or otherwise at increased risk of bleeding, there are regularly updated guidelines available from the American Society of Regional Anesthesia that should be followed for such an regional analgesia.[94]

For long-term pain management, local anesthetic should be continuously infused through a catheter, and infection risk should be clearly considered.[18] As mentioned above, opioids have immunomodulating properties, and a regional analgesia through a catheter requires extra caution in patients taking opioids frequently.[77,78] Regional analgesia should be per-

Table 4. Factors have to be considered in the use of regional analgesia

\footnotetext{
Pain can be relieved easily by simple methods such as repositioning or fixation of limb or body

Have to treat after identification and adjustment of other causes of pain such as fixation, adjustment (e.g., withdrawal of endotracheal tube), or removal of devices

Anatomically localized pain in a specific region such as postoperative or procedural pain is amenable to regional analgesic techniques

Patient's level of consciousness has to be enough to evaluate the effectiveness of regional analgesia

Regional analgesic techniques are contraindicated in the following conditions: patient refusal, local infection at the needle insertion site, preexisting neuropathy, local anesthetic allergies, severe bleeding tendency

Risks can be reduced during the regional analgesia through use of ultrasound, tunneled catheters, correction of severe bleeding tendency
} 
formed after considering possible infections associated with catheterization or patient's underlying illness such as sepsis.[18] When Regional analgesia is performed with a continuous catheter, the catheter should be not removed unless there are any signs of an infection.[79]

Table 4 summarizes information that should be noted to perform a regional analgesic technique in adult ICU patient. More importantly, regional anesthetic techniques can be used appropriately for pain management in adult ICU patients provided the following four conditions are met.[18,30] First, the extent to which regional anesthesia influences patient conditions should be accurately considered. Secondly, fully experienced anesthesiologist, pain physician or intensivist trained in anesthesiology and pain medicine is available to perform a variety of anesthetic techniques. Thirdly, well-experienced nurses who are able to identify complications related to surgical procedures or early warning signs of complications are available. Lastly, the ICU should be operated in a systematic way to provide an aseptic condition for catheter placement, regular inspection of devices and early detection of infection. However, these conditions are not met in many ICU settings, and the methods described in Table 3 is not widely used. Above all, there is not enough evidence that support the use of regional analgesia for pain management in the ICU. Further investigations are needed to improve the current pain control practices in the critical care setting, which demands more evidence to accept benefits of regional analgesia and further information to count adverse effects associated with regional analgesic techniques.[30]

In addition to regional analgesic techniques, non-pharmacologic pain treatments also include music therapy, relaxation techniques, and non-pharmacologic complementary interventions like provision of information.[30,31,95-97] These techniques are easy, safe and economic to perform. Regional analgesia is not widely used for ICU patients amid insufficient investigations and lack of evidence to support benefits. However, regional analgesia will provide a new direction toward pain management in adult ICU patients by reducing the use of opioids and improving pain relief.[29,30,33]

\section{Conclusion}

The assessment and treatment of pain is not done properly for adult ICU patients, even though they may suffer from quite severe pain, largely because they cannot verbally express their pain. If pain in adult ICU patients can be assessed more accu- rately based on patient characteristics and treated by multidisciplinary cares, including pharmacologic and non-pharmacologic methods, their pain and stress response can be controlled successfully, leading to a decrease in PTSD.

\section{References}

1) American Pain Society: Principles of analgesic use in the treatment of acute pain and cancer pain. 4th ed. Glenview (IL), American Pain Society. 1999.

2) Payen JF, Bosson JL, Chanques G, Mantz J, Labarere J; DOLOREA Investigators: Pain assessment is associated with decreased duration of mechanical ventilation in the intensive care unit: a post Hoc analysis of the DOLOREA study. Anesthesiology 2009; 111: 1308-16.

3) Jacobi J, Fraser GL, Coursin DB, Riker RR, Fontaine D, Wittbrodt ET, et al: Clinical practice guidelines for the sustained use of sedatives and analgesics in the critically ill adult. Crit Care Med 2002; 30: 119-41

4) Higgins TL, Jodka PG, Farid A: Pharmacologic approaches to sedation, pain relief and neuromuscular blockade in the intensive care unit. part II: Analgesia Clin Intensive Care 2003; 14: $91-8$

5) Hamill-Ruth RJ, Marohn ML: Evaluation of pain in the critically ill patient. Crit Care Clin 1999; 15: 35-54.

6) Drayer RA, Henderson J, Reidenberg M: Barriers to better pain control in hospitalized patients. J Pain Symptom Manage 1999; 17: 434-40.

7) Cade $\mathrm{CH}$ : Clinical tools for the assessment of pain in sedated critically ill adults. Nurs Crit Care 2008; 13: 288-97.

8) Kwekkeboom KL, Herr K: Assessment of pain in the critically ill. Crit Care Nurs Clin North Am 2001; 13: 181-94.

9) Azzam PN, Alam A: Pain in the ICU: a psychiatric perspective. J Intensive Care Med 2013; 28: 140-50.

10) Stein-Parbury J, McKinley S: Patients' experiences of being in an intensive care unit: a select literature review. Am J Crit Care 2000; 9: 20-7.

11) Swinamer DL, Phang PT, Jones RL, Grace M, King EG: Effect of routine administration of analgesia on energy expenditure in critically ill patients. Chest 1988; 93: 4-10.

12) Page GG, Blakely WP, Ben-Eliyahu S: Evidence that postoperative pain is a mediator of the tumor-promoting effects of surgery in rats. Pain 2001; 90: 191-9.

13) Myhren H, Ekeberg O, Toien K, Karlsson S, Stokland O: Posttraumatic stress, anxiety and depression symptoms in 
patients during the first year post intensive care unit discharge. Crit Care 2010; 14: R14.

14) Merskey H, Bogduk N: Classification of chronic pain. Seattle, IASP Press. 1994, p 210.

15) Cross SA: Pathophysiology of pain. Mayo Clin Proc 1994; 69: 375-83.

16) Willis WD, Westlund KN: Neuroanatomy of the pain system and of the pathways that modulate pain. J Clin Neurophysiol 1997; 14: 2-31.

17) Epstein J, Breslow MJ: The stress response of critical illness. Crit Care Clin 1999; 15: 17-33, v.

18) Lindenbaum L, Milia DJ: Pain management in the ICU. Surg Clin North Am 2012; 92: 1621-36.

19) Desai PM: Pain management and pulmonary dysfunction. Crit Care Clin 1999; 15: 151-66, vii.

20) Dünser MW, Hasibeder WR: Sympathetic overstimulation during critical illness: adverse effects of adrenergic stress. J Intensive Care Med 2009; 24: 293-316.

21) Hall JE: The autonomic nervous system and the adrenal medulla. In: Textbook of medical physiology. 12th ed. Edited by Hall JE, Guyton AC: St. Louis, Saunders. 2011, pp 729-41.

22) Brame AL, Singer M: Stressing the obvious? An allostatic look at critical illness. Crit Care Med 2010; 38: S600-7.

23) Davydow DS, Zatzick DF, Rivara FP, Jurkovich GJ, Wang J, Roy-Byrne PP, et al: Predictors of posttraumatic stress disorder and return to usual major activity in traumatically injured intensive care unit survivors. Gen Hosp Psychiatry 2009; 31: 428-35.

24) Pervanidou P: Biology of post-traumatic stress disorder in childhood and adolescence. J Neuroendocrinol 2008; 20: 632-8.

25) Lemieux AM, Coe CL: Abuse-related posttraumatic stress disorder: evidence for chronic neuroendocrine activation in women. Psychosom Med 1995; 57: 105-15.

26) Mason JW, Giller EL, Kosten TR, Harkness L: Elevation of urinary norepinephrine/cortisol ratio in posttraumatic stress disorder. J Nerv Ment Dis 1988; 176: 498-502.

27) Geracioti TD Jr, Baker DG, Ekhator NN, West SA, Hill KK, Bruce $\mathrm{AB}$, et al: CSF norepinephrine concentrations in posttraumatic stress disorder. Am J Psychiatry 2001; 158: 1227-30.

28) Taylor FB, Lowe K, Thompson C, McFall MM, Peskind ER, Kanter ED, et al: Daytime prazosin reduces psychological distress to trauma specific cues in civilian trauma posttraumatic stress disorder. Biol Psychiatry 2006; 59: 577-81.
29) Barr J, Fraser GL, Puntillo K, Ely EW, Gélinas C, Dasta JF, et al: Clinical practice guidelines for the management of pain, agitation, and delirium in adult patients in the intensive care unit. Crit Care Med 2013; 41: 263-306.

30) Mularski RA, Sessler CN, Schmidt GA: Pain management in the intensive care unit. In: Bonica's management of pain. 4th ed. Edited by Fishman SM, Ballantyne JC, Rathmell JP: Philadelphia, Wolters Kluwer/Lippincott Williams \& Wilkins. 2010, pp 1587-602.

31) Erstad BL, Puntillo K, Gilbert HC, Grap MJ, Li D, Medina J, et al: Pain management principles in the critically ill. Chest 2009; 135: 1075-86.

32) Payen JF, Chanques G, Mantz J, Hercule C, Auriant I, Leguillou JL, et al: Current practices in sedation and analgesia for mechanically ventilated critically ill patients: A prospective multi-center patient-based study. Anesthesiology 2007; 106: 687-95.

33) Sessler CN, Muzevich KM: Use of sedatives, analgesics, and neuromuscular blockers. In: Critical care medicine : principles of diagnosis and management in the adult. 4th ed. Edited by Parrillo JE, Dellinger RP: Philadelphia, Elsevier/Saunders. 2014, pp 255-71.

34) Gélinas C, Tousignant-Laflamme Y, Tanguay A, Bourgault P: Exploring the validity of the bispectral index, the CriticalCare Pain Observation Tool and vital signs for the detection of pain in sedated and mechanically ventilated critically ill adults: a pilot study. Intensive Crit Care Nurs 2011; 27: 46-52.

35) Breivik H, Borchgrevink PC, Allen SM, Rosseland LA, Romundstad L, Hals EK, et al: Assessment of pain. Br J Anaesth 2008; 101: 17-24.

36) Herr K, Coyne PJ, Key T, Manworren R, McCaffery M, Merkel S, et al: Pain assessment in the nonverbal patient: position statement with clinical practice recommendations. Pain Manag Nurs 2006; 7: 44-52.

37) Christoph SB: Pain assessment. The problem of pain in the critically ill patient. Crit Care Nurs Clin North Am 1991; 3: 11-6.

38) Kaiser KS: Assessment and management of pain in the critically ill trauma patient. Crit Care Nurs Q 1992; 15: 14-34.

39) Puntillo KA, Morris AB, Thompson CL, Stanik-Hutt J, White CA, Wild LR: Pain behaviors observed during six common procedures: results from Thunder project II. Crit Care Med 2004; 32: 421-7.

40) Gélinas C, Fillion L, Puntillo KA: Item selection and content validity of the critical-care pain observation tool for non-ver- 
bal adults. J Adv Nurs 2009; 65: 203-16.

41) AGS Panel on Persistent Pain in Older Persons: The management of persistent pain in older persons. J Am Geriatr Soc 2002; 50(6 Suppl): S205-24.

42) Payen JF, Bru O, Bosson JL, Lagrasta A, Novel E, Deschaux I, et al: Assessing pain in critically ill sedated patients by using a behavioral pain scale. Crit Care Med 2001; 29: 2258-63.

43) Chanques G, Payen JF, Mercier G, de Lattre S, Viel E, Jung $\mathrm{B}$, et al: Assessing pain in non-intubated critically ill patients unable to self report: an adaptation of the behavioral pain scale. Intensive Care Med 2009; 35: 2060-7.

44) Gélinas C, Fillion L, Puntillo KA, Viens C, Fortier M: Validation of the critical- care pain observation tool in adult patients. Am J Crit Care 2006; 15: 420-7.

45) Gélinas C, Harel F, Fillion L, Puntillo KA, Johnston CC: Sensitivity and specificity of the critical-care pain observation tool for the detection of pain in intubated adults after cardiac surgery. J Pain Symptom Manage 2009; 37: 58-67.

46) Pisani MA, Ely EW: Monitoring and treatment of pain, anxiety, and delirium in the ICU. In: Clinical critical care medicine. Edited by Albert RK, Slutsky AS, Ranieri VM, Takala J, Torres A: Philadelphia, Mosby-Elsevier. 2006, pp $51-9$.

47) Watling SM, Dasta JF, Seidl EC: Sedatives, analgesics, and paralytics in the ICU. Ann Pharmacother 1997; 31: 148-53.

48) Nasraway SA Jr, Jacobi J, Murray MJ, Lumb PD; Task Force of the American College of Critical Care Medicine of the Society of Critical Care Medicine and the American Society of Health-System Pharmacists, American College of Chest Physicians: Sedation, analgesia, and neuromuscular blockade of the critically ill adult: revised clinical practice guidelines for 2002. Crit Care Med 2002; 30: 117-8.

49) Bion JF, Logan BK, Newman PM, Brodie MJ, Oliver JS, Aitchison TC, et al: Sedation in intensive care: Morphine and renal function. Intensive Care Med 1986; 12: 359-65.

50) Sessler CN, Varney K: Patient-focused sedation and analgesia in the ICU. Chest 2008; 133: 552-65.

51) Wilhelm W, Kreuer S: The place for short-acting opioids: Special emphasis on remifentanil. Crit Care 2008; 12 Suppl 3: S5.

52) Battershill AJ, Keating GM: Remifentanil : a review of its analgesic and sedative use in the intensive care unit. Drugs 2006; 66: 365-85.

53) Horn E, Nesbit SA: Pharmacology and pharmacokinetics of sedatives and analgesics. Gastrointest Endosc Clin N Am 2004; 14: 247-68.
54) Riker RR, Fraser GL: Adverse events associated with sedatives, analgesics, and other drugs that provide patient comfort in the intensive care unit. Pharmacotherapy 2005; 25(5 Pt 2): 8 S-18S.

55) Ehret GB, Voide C, Gex-Fabry M, Chabert J, Shah D, Broers $\mathrm{B}$, et al: Drug-induced long QT syndrome in injection drug users receiving methadone: High frequency in hospitalized patients and risk factors. Arch Intern Med 2006; 166: 1280-7.

56) De Oliveira GS Jr, Agarwal D, Benzon HT: Perioperative single dose ketorolac to prevent postoperative pain: A metaanalysis of randomized trials. Anesth Analg 2012; 114: 424-33.

57) Maund E, McDaid C, Rice S, Wright K, Jenkins B, Woolacott $\mathrm{N}$ : Paracetamol and selective and non-selective non-steroidal anti-inflammatory drugs for the reduction in morphine-related side-effects after major surgery: a systematic review. $\mathrm{Br}$ J Anaesth 2011; 106: 292-7.

58) De Oliveira GS Jr, Almeida MD, Benzon HT, McCarthy RJ: Perioperative single dose systemic dexamethasone for postoperative pain: A meta-analysis of randomized controlled trials. Anesthesiology 2011; 115: 575-88.

59) Laskowski K, Stirling A, McKay WP, Lim HJ: A systematic review of intravenous ketamine for postoperative analgesia. Can J Anaesth 2011; 58: 911-23.

60) Gilron I: Corticosteroids in postoperative pain management: future research directions for a multifaceted therapy. Acta Anaesthesiol Scand 2004; 48: 1221-2.

61) Pietz B, Lambrecht H, Prien T, Van Aken H: The strict separation of clinical and academic budgets: an analysis at a German medical university department of anaesthesia. Best Pract Res Clin Anaesthesiol 2002;1 6: 371-4.

62) Pettersson PH, Jakobsson J, Owall A: Intravenous acetaminophen reduced the use of opioids compared with oral administration after coronary artery bypass grafting. J Cardiothorac Vasc Anesth 2005; 19: 306-9.

63) Maddali MM, Kurian E, Fahr J: Extubation time, hemodynamic stability, and postoperative pain control in patients undergoing coronary artery bypass surgery: an evaluation of fentanyl, remifentanil, and nonsteroidal antiinflammatory drugs with propofol for perioperative and postoperative management. J Clin Anesth 2006; 18: 605-10.

64) Guillou N, Tanguy M, Seguin P, Branger B, Campion JP, Mallédant Y: The effects of small-dose ketamine on morphine consumption in surgical intensive care unit patients after major abdominal surgery. Anesth Analg 2003; 97: 843-7.

65) Memis D, Inal MT, Kavalci G, Sezer A, Sut N: Intravenous 
paracetamol reduced the use of opioids, extubation time, and opioid-related adverse effects after major surgery in intensive care unit. J Crit Care 2010; 25: 458-62.

66) Candiotti KA, Bergese SD, Viscusi ER, Singla SK, Royal MA, Singla NK: Safety of multiple-dose intravenous acetaminophen in adult inpatients. Pain Med 2010; 11: 1841-8.

67) Groudine SB, Fisher HA, Kaufman RP Jr, Patel MK, Wilkins LJ, Mehta SA, et al: Intravenous lidocaine speeds the return of bowel function, decreases postoperative pain, and shortens hospital stay in patients undergoing radical retropubic prostatectomy. Anesth Analg 1998; 86: 235-9.

68) Pandharipande PP, Pun BT, Herr DL, Maze M, Girard TD, Miller RR, et al: Effect of sedation with dexmedetomidine vs lorazepam on acute brain dysfunction in mechanically ventilated patients: the MENDS randomized controlled trial. JAMA 2007; 298: 2644-53.

69) Eisenberg E, Peterson D: Neuropathic pain pharmacotherapy. In: Bonica's management of pain. 4th ed. Edited by Fishman SM, Ballantyne JC, Rathmell JP: Philadelphia, Wolters Kluwer/Lippincott Williams \& Wilkins. 2010, pp 1194-207.

70) Erstad BL, Chopda S, Esser MJ: Prescribing of analgesics in trauma patients. Am J Ther 1997; 4: 27-30.

71) Naber L, Jones G, Halm M: Epidural analgesia for effective pain control. Crit Care Nurse 1994; 14: 69-72, 77-83; quiz 84-5.

72) Rudin A, Flisberg P, Johansson J, Walther B, Lundberg CJ: Thoracic epidural analgesia or intravenous morphine analgesia after thoracoabdominal esophagectomy: a prospective follow-up of 201 patients. J Cardiothorac Vasc Anesth 2005; 19: $350-7$.

73) Lee CS, Han JU, Kim TJ, Chung CK, Lim HK, Cha YD, et al: Effect of continuous epidural block on the duration of intensive care after cardiac surgery. Korean J Crit Care Med 2000; 15: 41-6.

74) Liu S, Carpenter RL, Neal JM: Epidural anesthesia and analgesia. Their role in postoperative outcome. Anesthesiology 1995; 82: 1474-506.

75) Nishimori M, Ballantyne JC, Low JH: Epidural pain relief versus systemic opioid-based pain relief for abdominal aortic surgery. Cochrane Database Syst Rev 2006; (3): CD005059.

76) Low JH: Survey of epidural analgesia management in general intensive care units in England. Acta Anaesthesiol Scand 2002; 46: 799-805.

77) Chang SL, Beltran JA, Swarup S: Expression of the mu opioid receptor in the human immunodeficiency virus type 1 transgenic rat model. J Virol 2007; 81: 8406-11.
78) Feng P, Truant AL, Meissler JJ Jr, Gaughan JP, Adler MW, Eisenstein TK: Morphine withdrawal lowers host defense to enteric bacteria: spontaneous sepsis and increased sensitivity to oral Salmonella enterica serovar Typhimurium infection. Infect Immun 2006; 74: 5221-6.

79) Schulz-Stübner S, Boezaart A, Hata JS: Regional analgesia in the critically ill. Crit Care Med 2005; 33: 1400-7.

80) Finlayson BJ, Underhill TJ: Femoral nerve block for analgesia in fractures of the femoral neck. Arch Emerg Med 1988; 5: 173-6.

81) Tan TT, Coleman MM: Femoral blockade for fractured neck of femur in the emergency department. Ann Emerg Med 2003; 42: 596-7.

82) Lopez S, Gros T, Bernard N, Plasse C, Capdevila X: Fascia iliaca compartment block for femoral bone fractures in prehospital care. Reg Anesth Pain Med 2003; 28: 203-7.

83) Cuignet O, Pirson J, Boughrouph J, Duville D: The efficacy of continuous fascia iliaca compartment block for pain management in burn patients undergoing skin grafting procedures. Anesth Analg 2004; 98: 1077-81.

84) Kaden V, Wölfel H, Kirsch W: [Experiences with a combined sciatic and femoral block in surgery of injuries of the lower leg]. Anaesthesiol Reanim 1989; 14: 299-303. German.

85) Park WY, Thompson JS, Lee KK: Effect of epidural anesthesia and analgesia on perioperative outcome: a randomized, controlled Veterans Affairs cooperative study. Ann Surg 2001; 234: 560-9.

86) Tziavrangos E, Schug SA: Regional anaesthesia and perioperative outcome. Curr Opin Anaesthesiol 2006; 19: 521-5.

87) Bulger EM, Edwards T, Klotz P, Jurkovich GJ: Epidural analgesia improves outcome after multiple rib fractures. Surgery 2004; 136: 426-30.

88) Lloyd DG, Ma D, Vizcaychipi MP: Cognitive decline after anaesthesia and critical care. Cont Educ Anaesth Crit Care Pain 2012; 12: 105-9.

89) Rudolph JL, Marcantonio ER: Review articles: postoperative delirium: acute change with long-term implications. Anesth Analg 2011; 112: 1202-11.

90) Marhofer P, Chan VW: Ultrasound-guided regional anesthesia: current concepts and future trends. Anesth Analg 2007; 104: 1265-90.

91) Bigeleisen PE: Ultrasound-guided infraclavicular block in an anticoagulated and anesthetized patient. Anesth Analg 2007; 104: 1285-7.

92) Kress JP, Pohlman AS, O'Connor MF, Hall JB: Daily interruption of sedative infusions in critically ill patients under- 
going mechanical ventilation. N Engl J Med 2000; 342: 1471-7.

93) Girard TD, Kress JP, Fuchs BD, Thomason JW, Schweickert WD, Pun BT, et al: Efficacy and safety of a paired sedation and ventilator weaning protocol for mechanically ventilated patients in intensive care (Awakening and Breathing Controlled trial): a randomised controlled trial. Lancet 2008; 371: 126-34.

94) Horlocker TT, Wedel DJ, Rowlingson JC, Enneking FK, Kopp SL, Benzon HT, et al: Regional anesthesia in the patient receiving antithrombotic or thrombolytic therapy: American Society of Regional Anesthesia and Pain Medicine
Evidence-Based Guidelines (Third Edition). Reg Anesth Pain Med 2010; 35: 64-101.

95) Cepeda MS, Carr DB, Lau J, Alvarez H: Music for pain relief. Cochrane Database Syst Rev Cochrane Database Syst Rev 2006; (2): CD004843.

96) Kwekkeboom KL, Gretarsdottir E: Systematic review of relaxation interventions for pain. J Nurs Scholarsh 2006; 38: 269-77.

97) Suls J, Wan CK: Effects of sensory and procedural information on coping with stressful medical procedures and pain: a meta-analysis. J Consult Clin Psychol 1989; 57: 372-9. 